\title{
Erratum to: Prevalence of type 2 diabetes in Germany in 2040: estimates from an epidemiological model
}

\author{
Ralph Brinks • Teresa Tamayo • Bernd Kowall • \\ Wolfgang Rathmann
}

Published online: 15 September 2012

(C) Springer Science+Business Media B.V. 2012

\section{Erratum to: Eur J Epidemiol}

\section{DOI 10.1007/s10654-012-9726-2}

The right part of Fig. 3 does not show the prevalence of type 2 diabetes as stated in the figure caption. The correct Fig. 3 appears below.

Fig. 3 Number (left) and prevalence (right) of males (dashed) and females (dotted) with type 2 diabetes aged 55-74 from 2010 to 2040 in the base case scenario
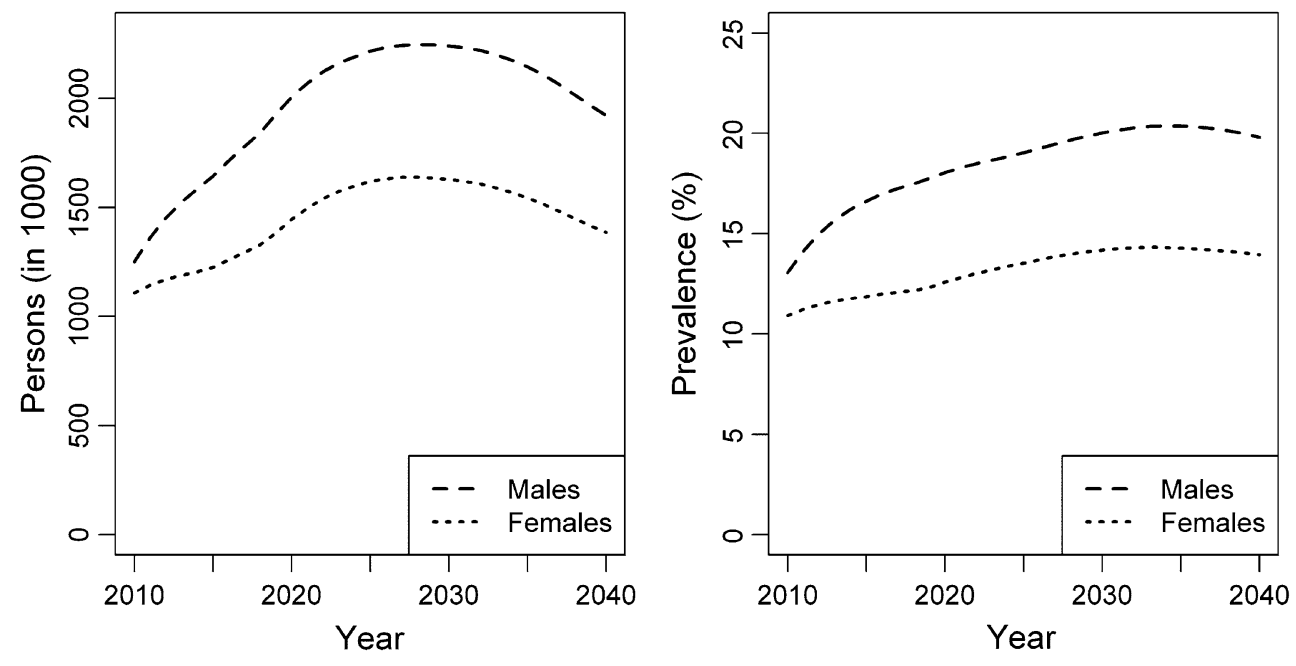

The online version of the original article can be found under doi:10.1007/s10654-012-9726-2. 